Hydrology and Earth System Sciences, 7(4), 431-435 (2003) C EGU

\title{
Predicting recovery of acidified freshwaters in Europe and Canada: an introduction
}

\author{
R.C. Ferrier ${ }^{1}$, R.F. Wright ${ }^{2}$, A. Jenkins ${ }^{3}$ and H. Barth ${ }^{4}$ \\ ${ }^{1}$ Macaulay Institute, Craigiebuckler, Aberdeen, AB15 8QH, UK \\ ${ }^{2}$ Centre for Ecology and Hydrology, Wallingford, Oxon OX10 8BB, UK \\ ${ }^{3}$ Norwegian Institute for Water Research, PO Box 173, Kjelsas, N-0411 Oslo, Norway \\ ${ }^{4}$ European Commission Research Directorate General, Environment and Sustainable Development Programme, Unit I-3, B-1049 Bruxelles, Belgium
}

Email for corresponding author: r.ferrier@macaulay.ac.uk

\begin{abstract}
The RECOVER:2010 project was designed to assess the current and future anthropogenic pressures on sensitive European freshwater ecosystems. This pan-European assessment utilised a standardised predictive modelling approach to evaluate the degree of compliance with respect to the restoration of acidified waters by 2016, as specified under the EU Water Framework Directive (WFD), and evaluated the environmental benefits of proposed UN-ECE protocols on emissions control. Between 1970 and 2000, observations and model simulations show a significant decline in acidic surface water in all regions of Europe. This demonstrated the success of policies aimed at reducing emission of acidifying compounds. The nature and extent of future regional recovery from acidification is, however, dependent upon the historical pattern of deposition, regional ecosystem characteristics and the role of confounding factors, which may delay the onset of recovery or the magnitude of response. Model predictions to 2010 and beyond emphasise the continued benefit of currently proposed reductions, as reflected by the degree of recovery of freshwater ecosystems. A key component was to link such hydrochemical recovery with ecological response, and the project aimed to evaluate this against current WFD criteria of "good status" and "reference conditions". The RECOVER:2010 project research has also played a major role in defining the dynamic modelling outputs which will be required to support the review of the Gothenburg Protocol within the work of the UN-ECE CLRTAP Working Group on Effects (WGE), and model outputs have been made available to a range of national agencies throughout Europe.
\end{abstract}

Keywords: recovery, acidification, modelling, policy, good status, reference conditions

\section{Introduction}

As industrialisation increased across Europe and North America in the mid $19^{\text {th }}$ century, the emission of potentially acidifying compounds accelerated through the burning of fossil fuels, metal smelting, agricultural expansion, urbanisation and transport. The resultant transport and deposition of oxides of sulphur (S) and nitrogen $(\mathrm{N})$ resulted in the widespread acidification of many terrestrial and aquatic ecosystems. Within Europe, international agreements under the United Nations Economic Council for Europe (UN-ECE) Convention on Long-Range Transboundary Air Pollution (LTRAP) implemented measures through which to reduce emissions of acidifying pollutants (Bull et al., 2001). Key recent steps have been the 1999 Gothenburg Protocol, and the EU National Emission Ceilings Directive (NEC). The NEC limits national emissions of S, oxidised and reduced $\mathrm{N}$ and Volatile Organic Compounds (VOC) (Skeffington, 2002). If implemented these measures will continue the downward trend in emissions.

The RECOVER:2010 project was designed to assess the impact of such current and future anthropogenic pressures on sensitive European freshwater ecosystems (Ferrier et al., 2001). The first phase of the project determined the extent of recovery of European freshwaters from acidification pressures during the period 1970-2000. The results were published in 2001 as a special issue of Hydrology and Earth System Sciences (Ferrier et al., 2001). 
This analysis highlighted the important role of potentially confounding factors influencing the scale and magnitude of regional recovery patterns. In particular, climatic drivers such as the North Atlantic Oscillation (Evans and Monteith, 2001), and the deposition of sea-salt in northern and western Europe (Helliwell et al., 2001; Neal et al., 2001; Wright and Jenkins, 2001) and of dust material from the atmosphere in Mediterranean Europe (Rogora et al., 2001). Similarly, the degree of reversibility in any given location was also shown to be a function of relative and absolute deposition reductions and the physio-chemical characteristics of individual catchments.

Results of this pan-European assessment indicated that there was a general reduction in surface water acid anion concentration and a concomitant increase in acid neutralising capacity (ANC). This was generally mirrored in an increase in $\mathrm{pH}$ and a decrease in aluminium (Evans et al., 2001). The monitoring data collected from Europe showed clearly that reductions in the emission of acidifying pollutants have had a significant positive effect on surface water quality. Further recovery should occur in the future as emissions continue to decline, although there may be time lags in ecosystem response.

The key objectives for the second phase of the RECOVER:2010 project were to:

1. Apply and validate regional dynamic models including the consideration of confounding factors.

2. Predict recovery into the future for European freshwater systems under currently agreed legislation (the CLE scenario).

3. Estimate the time required for these sensitive freshwater systems to recover to good ecological status.

4. Consider the implications for ecological recovery, particularly in relation to the targets of the EU Water Framework Directive.

To undertake such an analysis, a key task of the RECOVER:2010 project was to improve existing modelling tools and application procedures. This work included a new version of the MAGIC model (Cosby et al., 2001), which was then used in most of the regions. Collaboration involved national work in Finland with the SMART model (Posch et al., 2003), modelling activities with the EU project EMERGE at three reference regions; central Norway, northern Scotland and the Spanish Pyrenees, and MAGIC applications in two regions of Canada.

The EU Water Framework Directive (European Commission, 2000) provided the policy platform for the RECOVER:2010 project. This Directive commits Member States to achieve good surface water status by the year 2016 .
Here it is important to develop a set of procedures to evaluate the consequences of remediation measures. The use of enhanced biogeochemical models allows for that evaluation for surface waters impacted by acidification. The MAGIC model has been used to reconstruct the hydrochemistry of regional lake water quality in pre-acidification times, and this gives an initial or 'reference' condition. If this hydrochemical signal can be linked to a given ecology, such as that defined from paleo-reconstruction (Battarbee et al., 1990), then deviation from those reference conditions (the so called 'Ecological Quality Ratio') will provide the basis for the determination of the magnitude of historical anthropogenic impact.

Changes in water chemistry are well correlated to effects on target species of diatoms, invertebrates and fish (Lien et al., 1996; Juggins et al., 1995; McCartney et al., in press). These studies relate ANC to probability of damage. Such relationships provide the basis for assessment of whether the implementation of the CLE scenario could achieve sufficient improvement in the chemical status of the water bodies to allow for recovery to good ecological status. Additional constraints placed on aquatic ecosystems such as colonisation rates, dispersal, lifecycles and behaviour, and species interactions add additional time lags to recovery that may range from years to decades (Raddum et al., 2001; Raddum and Fjellheim, 2003).

\section{Structure of the Volume}

The future patterns of acid deposition in response to the CLE scenario (Schopp et al., 2003) give the starting conditions for modelling future trends in surface water quality. The standardised approach utilises the RAINS (Regional Acidification and Information System (Amman et al., 1998)) emissions model and the EMEP deposition model (EMEP, 1998), and ensured compatibility between different regional modelling assessments undertaken as part of RECOVER:2010 (Helliwell et al., 2003; Wright and Cosby 2003; Posch et al., 2003; Majer et al., 2003: Kopacek et al., 2003; Hruska et al., 2003; Rogora et al., 2003; Pretchel et al., 2003). Several of the regional studies also took account of important localised driving variables such as land use (Helliwell et al., 2003), soil sulphur dynamics (Pretchel et al., 2003), catchment characteristics (Majer et al., 2003; Kopacek et al., 2003), and atmospheric deposition of dust (Rogora et al., 2003).

The first Special Issue of the RECOVER:2010 project (Ferrier et al., 2001), highlighted the importance of interactions of such confounding factors and observed patterns of deposition at a regional scale, in off-setting potential recovery. The importance of such interactions is 
further supported by the analyses of Dillon et al. (2003a; 2003b), who carried out coherence analysis on spatial and temporal sulphate concentrations in Norwegian and Canadian lakes. There was clear evidence that although lake chemistry in both regions responds to changes in deposition, this change was influenced by large-scale climate factors, such as the Artic and North Atlantic Oscillation Indices (AOI and NAOI), and the Southern and El Niño Southern Oscillation Indices (SOI and ENSOI).

Methodologies for up-scaling responses from the regional level to the national and international scale has been the subject of much debate (Ferrier, 1998), and there must be a balance between the scale of model output and the scale addressed by the questions posed by decision makers. This requires a trade-off between model complexity and data availability. The RECOVER:2010 project did not model every acidified freshwater ecosystem within Europe; rather the focus was on key regions and representative ecosystems where acidification impacts had been recorded and site specific and regional data were available (Fig. 1).

A pan-European scale assessment has been undertaken (Jenkins et al., 2003a), which includes regional studies

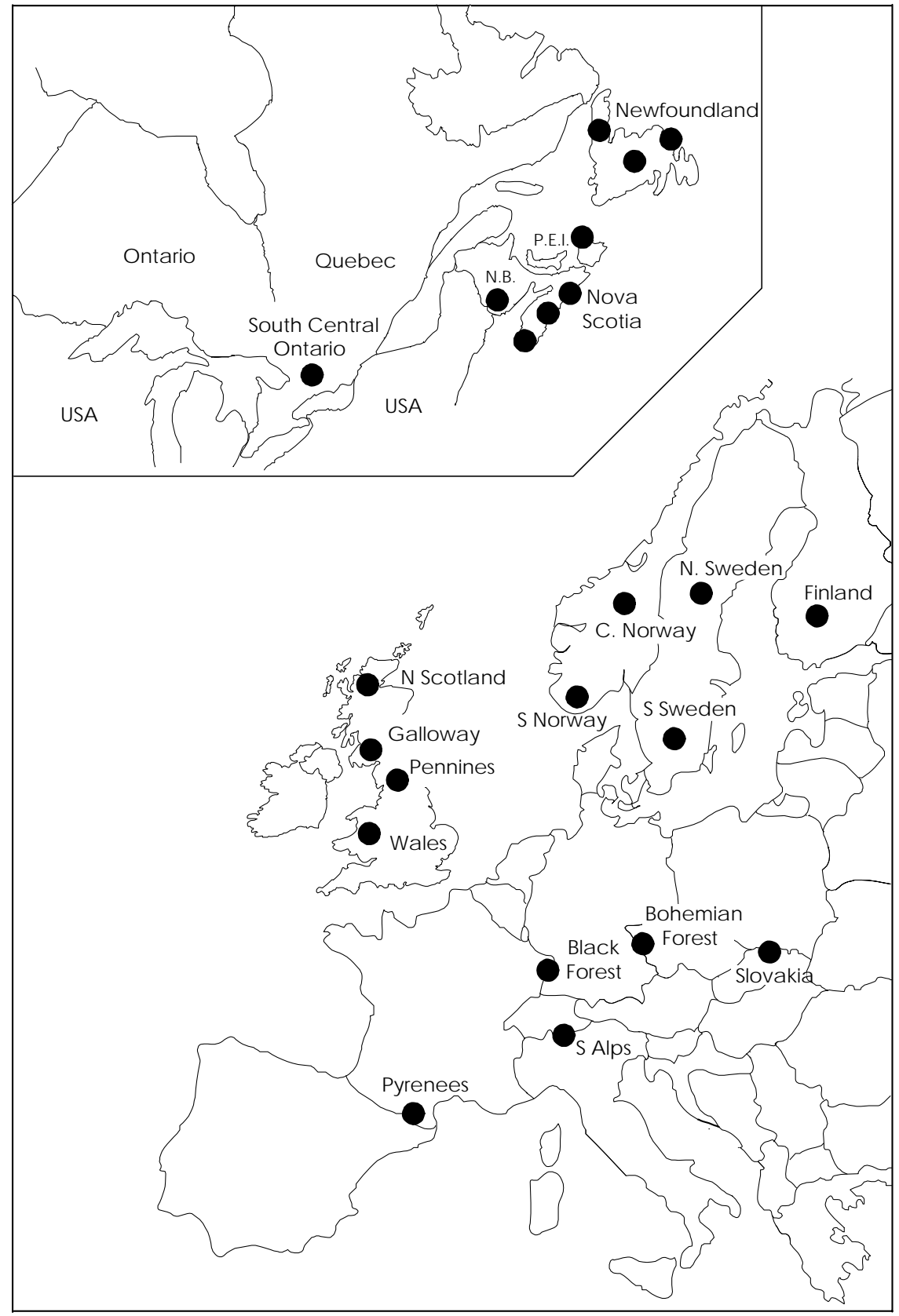

Fig. 1 Location of modelled regions within the RECOVER, EMERGE and Canadian Studies 
undertaken as part of the EU EMERGE project and national research in Finland. The general picture shows that substantial improvements in water quality are expected within the next two decades throughout Europe, assuming that the emission reductions agreed under the CLE scenario are implemented as planned by the target year of 2010. A similar picture is apparent from studies in Canada, in particular in south central Ontario (Aherne et al., 2003), and the Atlantic Provinces (Clair et al., 2003) where current legislation has resulted in notable improvements in water quality. It is also clear however, that additional emissions reductions are necessary to return lake chemistry to original conditions through much of these regions.

With respect to fulfilment of the WFD requirement to achieve recovery to reference conditions, the picture is less optimistic. Analysis suggests that further emission reductions will be necessary to obtain water quality suitable for fish and other key indicator organisms in parts of the UK, southern Fennoscandia and the Alps (Jenkins et al., 2003a).

Dynamic models can also be used to assist in the optimisation of further emissions reductions. The final paper in the Special Issue offers an innovative and novel way forward for the use of dynamic models in policy development through deriving a so-called target load function (TLF) for use in integrated assessment (Jenkins et al., 2003b). TLF is a further development of the concept of critical loads by introducing the time aspects. The TLF can be used to determine the deposition load necessary to restore a damaged ecosystem to the critical chemical limit for a key organism by a given time. The potential use of TLF in regional, national and international assessments is most promising; TLF plays a role in providing scientific information for use in specification of new protocols under the UN-ECE LTRAP Convention.

The RECOVER:2010 website is located at: http:// www.macaulay.ac.uk/recover/index.html

\section{Acknowledgements}

The RECOVER:2010 project was funded in part by the European Commission's Environment and Sustainable Development Programme (Key Action on Sustainable Management and Quality of Water under contract EVK1CT-1999-00018), The Natural Environment Research Council Centre for Ecology and Hydrology (UK), the Scottish Executive Environment and Rural Affairs Department (SEERAD), Department of the Environment, Food and Rural Affairs (Contract No. EPG 1/3/194), and the Norwegian Institute for Water Research (NIVA). Thanks are due to colleagues who assisted in data compilation., to collaborators in the EMERGE project (EVK1-CT-199900032), in the Finnish Environment Institute (SYKE) and in the US and Canada. The latter were supported by Environment Canada, Natural Sciences and Engineering Research Council of Canada, Ontario Power Generation Inc, and the Ontario Ministry of the Environment. The RECOVER:2010 project is particularly indebted to the 'enduser' forum composed of representatives of international, national and regional agencies in identifying pertinent and representative targets for the assessment of regional recovery, and for helping to optimise information dissemination. Thanks are also due to Rachel Helliwell (Macaulay Institute) who tirelessly ensured efficient administration of RECOVER:2010. Finally, the authors thank Charlene Nash (Macaulay Institute) for cocoordinating the compilation, review and editing of this Special Issue, and the authors and reviewers of the individual manuscripts who responded so enthusiastically to requests and deadlines.

\section{References}

Aherne, J., Dillon, P.J. and Cosby, B.J., 2003. Acidification and recovery of aquatic ecosystems in south-central Ontario, Canada: regional application of the MAGIC model. Hydrol. Earth Syst. Sci., 7, 561-573.

Amann, M., Bertok, I., Cofala, J., Gyarfas, F., Heyes, C., Klimont, Z., Makowski, M., Schöpp, W. and Shibayev, S., 1998. Cost effective control of acidification and ground level ozone. ISBN 92-828-4346-7, European Community, Brussels.

Battarbee, R.W., Mason, J., Renberg, I. and Talling, J.F., 1990. Paleolimnology and lake acidification. Phil. Trans. Royal Soc. Series B, 327, 223-445.

Bull, K.R., Achermann, B., Bashkin, V., Chrast, R., Fenech, G., Forsius, M., Gregor, H-D., Guardans, R., Haussmann, T., Hayes, F., Hettelingh, J.P., Johannessen, T., Krzyzanowski, M., Kucera, V., Kvæven, B., Lorenz, M., Lundin, L., Mills, G., Posch, M., Skjelkvåle, B.L. and Ulstein, M.J., 2001. Coordinated effects monitoring and modelling for developing and supporting international air pollution control agreements. Water Air Soil Pollut., 130, 119-130.

Clair, T.A., Dennis, I. and Cosby, B.J., 2003. Probable changes in lake chemistry in Canada's Atlantic Provinces under proposed North American emission reductions. Hydrol. Earth Syst. Sci., 7, 574-582.

Cosby, B.J., Ferrier, R.C., Jenkins, A. and Wright, R.F., 2001. Modelling the effects of acid deposition: refinements, adjustments and inclusion of nitrogen dynamics in the MAGIC model. Hydrol. Earth Syst. Sci., 5, 499-517.

Dillon, P.J., Somers, K.M., Findeis, J. and Eimers, M.C., 2003 a. Coherent response of lakes in Ontario, Canada to reductions in sulphur deposition: the effects of climate on sulphate concentrations. Hydrol. Earth Syst. Sci., 7, 583-595 .

Dillon, P.J., Skjelkvåle, B.L., Somers, K.M. and Tørseth, K., 2003b. Coherent responses of sulphate concentration in Norwegian lakes: relationships with sulphur deposition and climate indices. Hydrol. Earth Syst. Sci., 7, 596-608

EMEP, 1998. Transboundary acidifying air pollution in Europe. EMEP/MSC-W Report 1/98 Norwegian Metrological Institute, Oslo, Norway. 150pp. 
European Commission, 2000. Directive 2000/60/EC of the European Parliament and of the Council of 23 October 2000 establishing a framework for community action in the field of water policy. Official Journal L327 of 22.12.2000.

Evans, C.D. and Monteith, D.T., 2001. Chemical trends at lakes and streams in the UK Acid Waters Monitoring Network, 19882000: Evidence for recent recovery at a national scale. Hydrol. Earth Syst. Sci., 5, 351-366.

Evans, C.D., Cullen, J.M., Alewell, C., Kopácek, J., Marchetto, A., Moldan, F., Prechtel, A., Rogora, M., Vesely, J. and Wright, R.F., 2001. Recovery from acidification in European surface waters. Hydrol. Earth Syst. Sci., 5, 283-297.

Ferrier, R.C., 1998. The DYNAMO project: An Introduction. Hydrol. Earth Syst. Sci., 2, 375-383.

Ferrier, R.C., Jenkins, A., Wright, R.F., Schöpp, W. and Barth, H., 2001. Assessment of recovery of European surface waters from acidification 1970-2000: An introduction to the Special Issue. Hydrol. Earth Syst. Sci., 5, 274-282.

Helliwell, R.C., Ferrier, R.C., Johnston, L. and Goodwin, J., 2001. Land use influences on acidification and recovery of freshwaters in Galloway, south-west Scotland. Hydrol. Earth Syst. Sci., 5, 451-458.

Helliwell, R.C., Jenkins, A. and Ferrier, R.C., 2003. Modelling the recovery of surface water chemistry and the ecological implications in the British uplands. Hydrol. Earth Syst. Sci., 7, $456-466$.

Hruška, J. and Krám, P., 2003. Modelling long-term changes in streamwater and soil chemistry in catchments with contrasting vulnerability to acidification (Lysina and Pluhov Bor, Czech Republic). Hydrol. Earth Syst. Sci., 7, 525-539.

Jenkins, A., Camarero, L., Cosby, B.J., Ferrier, R.C., Forsuis, M., Helliwell, R.C., Kopácek, J., Majer, V., Molden, F., Posch, M., Rogora, M., Schöpp, W. and Wright, R.F., 2003a. A modelling assessment of acidification and recovery of European surface waters. Hydrol. Earth Syst. Sci., 7, 447-455.

Jenkins, A., Cosby, B.J., Ferrier, R.C. and Posch, M., 2003b. Assessing emission reduction targets with dynamic models: deriving target load functions for use in integrated assessment. Hydrol. Earth Syst. Sci., 7, 609-617.

Juggins, S., Ormerod, S.J. and Harriman, R., 1995. Relating critical loads to aquatic biota. In: Critical Loads of Acid Deposition for UK Freshwaters. Department of the Environment, London, UK.

Kopácek, J., Cosby, B.J., Majer, V., Stuchlík, E. and Veselý, J., 2003. Modelling reversibility of Central European mountain lakes from acidification: Part II - The Tatra Mountains. Hydrol. Earth Syst. Sci., 7, 510-524.

Lien, L., Raddum, G.G., Fjellheim, A. and Henriksen, A., 1996. A critical limit for acid neutralizing capacity in Norwegian surface waters, based on new analyses of fish and invertebrate responses. Sci. Total Environ., 177, 173-193.
Majer, V., Cosby, B.J., Kopácek, J. and Veselý, J., 2003. Modelling reversibility of Central European mountain lakes from acidification: Part I - The Bohemian Forest. Hydrol. Earth Syst. Sci. 7, 494-509.

McCartney, A.G., Harriman, R., Watt, A.W., Moore, D.W., Taylor, E.M., Collen, P. and Keay, E.J., 2003. Long term trends in pH, aluminium and dissolved organic carbon in Scottish fresh waters: implications for brown trout (Salmo trutta) survival. Sci. Total Environ., 310, 133-141.

Neal, C., Reynolds, B., Neal, M., Pugh, B., Hill, L. and Wickham, H., 2001. Long-term changes in the water quality of rainfall, cloud water and stream water for moorland, forested and clearfelled catchments at Plynlimon, mid-Wales. Hydrol. Earth Syst. Sci., 5, 459-476.

Posch, M., Forsius, M., Johansson, M., Vuorenmaa, J. and Kämäri, J., 2003. Modelling the recovery of acid-sensitive Finnish headwater lakes under present emission reduction agreements. Hydrol. Earth Syst. Sci., 7, 484-493.

Prechtel, A., Armbruster, M. and Matzner, E., 2003. Modelling sulphate stream concentrations in the Black Forest catchments Schluchsee and Villingen. Hydrol. Earth Syst. Sci., 7, 552-560.

Raddum, G.G., Fjellheim, A. and Skjelkvåle, B.L., 2001. Improvements in water quality and aquatic ecosystems due to reduction in sulphur deposition in Norway. Water Air Soil Pollut., 130, 87-98.

Raddum, G.G. and Fjellheim, A., 2003. Liming of River Audna, southern Norway. A large scale experiment of benthic invertebrate recovery. Ambio, 3, (in press).

Rogora, M.. Marchetto, A. and Mosello, R., 2001. Trends in the chemistry of atmospheric deposition and surface waters in the Lake Maggiore catchment. Hydrol. Earth Syst. Sci., 5, 379390.

Rogora, M., Marchetto, A. and Mosello, R., 2003. Modelling the effects of atmospheric sulphur and nitrogen deposition on selected lakes and streams of the Central Alps (Italy). Hydrol. Earth Syst. Sci., 7, 540-551.

Schöpp, W., Posch, M., Mylona, S. and Johansson, M., 2003. Long-term development of acid deposition (1880-2030) in sensitive freshwater regions in Europe. Hydrol. Earth Syst. Sci., 7, 436-446.

Skeffington, R., 2002. European nitrogen policies, nitrate in rivers and the use of the INCA model. Hydrol. Earth Syst. Sci., 6, $315-325$.

Wright, R.F. and Cosby, B.J., 2003. Future recovery of acidified lakes in Southern Norway predicted by the MAGIC model. Hydrol. Earth Syst. Sci. 7, 467-483.

Wright, R.F. and Jenkins, A., 2001. Climate change as a confounding factor in reversibility of acidification: RAIN and CLIMEX projects. Hydrol. Earth Syst. Sci., 5, 477-486. 